\title{
0 efeito da atividade física nas comorbidades psiquiátricas de pessoas com cefaleias primárias: Um estudo transversal da coorte do ELSA-Brasil
}

\author{
Arão Belitardo de Oliveira ${ }^{(D)}$, Mario Fernando Prieto Peres ${ }^{(D)}$, Juliane Prieto Peres Mercante ${ }^{(D)}$, \\ Maria del Carmen B. Molina ${ }^{\mathbb{D}}$, Paulo A. Lotufo ${ }^{\mathbb{D}}$, Isabela M. Benseñor ${ }^{\mathbb{D}}$, Alessandra C. Goulart ${ }^{\mathrm{D}}$ \\ Universidade de São Paulo, São Paulo, Brasil
}

Introdução

A atividade física (AF) está associada a menor prevalência de cefaleias primárias e transtornos psiquiátricos, mas seu efeito nessas comorbidade é desconhecido.

\section{Objetivo}

Estimar os efeitos de interação entre níveis de AF e cefaleias primárias como preditores de depressão e ansiedade.

\begin{abstract}
Métodos
Uma análise transversal no estudo ELSA-Brasil, modelos de regressão logística computaram a associação entre cefaleias primárias (ICHD-2) e depressão e ansiedade

(CIS-R). Interações entre níveis de AF (inativo, insuficientemente ativo, ativo e muito ativo no tempo de lazer e no deslocamento) com migrânea (definitiva e provável) e cefaleia do tipo tensão (CTT, definitiva e provável) foram estimados como preditores de depressão e ansiedade. Todos os modelos foram ajustados para dados sociodemográficos, fatores de risco cardiovascular e uso de medicamentos preventivos para migrânea.
\end{abstract}

\begin{abstract}
Resultados
Dados completos foram obtidos de 14.546 participantes, 54,3\% mulheres, mediana (IQR) da idade = 51 (45-58) anos. Todos as cefaleias primárias se associaram com maior frequência de depressão e/ou ansiedade. Em comparação com pessoas inativas sem cefaleias, os efeitos de interação de muito ativo/ativo com migrânea (definitiva e provável) e CTT provável anularam suas associações com depressão, enquanto muito ativo com CTT resultou em menor chance de depressão [OR (IC 95\%): 0,37 (0,16-0,81), p = 0,014]. Interações de muito ativo/ativo com provável migrânea e CTT (definitiva e provável) mostraram associação nula com ansiedade. No deslocamento, a interação de insuficientemente com CTT reduziu as chances de depressão [OR (IC 95\%): 0,48 (0,29-0,77), p=0,003], enquanto as interações de muito ativo/ativo com provável migrânea, CTT (definitiva e provável) anularam suas associações com depressão. Ativo com provável CTT resultou em associação nula com ansiedade.
\end{abstract}

\section{Conclusões}

No ELSA-Brasil, os níveis de AF representaram um atenuador da relação entre cefaleia e transtornos psiquiátricos.

Palavras-chave: Atividade física, Migrânea, Cefaleia do tipo tensão, Depressão, Ansiedade. 